\title{
Die Behandlung und Aufbewahrung von Injektionsspritzen und Injektionskanülen.
}

Von Marine-Stabsarzt a. D. Dr. Hans Kritzler, Frauenarzt in Erbach i. O.

Die Not der Zeit zwingt mit ihrer Teuerung auch den Arzt zu möglichst haushälterischer und sparsamer Verwendung und Handhabung seiner Gerätschaften, deren Preise bei der heutigen Geldentwertung ja teilweise in das Unerschwingliche gestiegen sind Es erscheint daher angebracht, kleine praktische Einrichtungen, die dem Arzt Mühe, Aerger und Kosten sparen, bekanntzumachen.

Wie behandelt der A rzt a m besten seine Spritzen und seine $\mathrm{Nadeln}$ ? - Es ist keine wissenschaftliche Frage, aber praktisch ist sie heutzutage durchaus bedeutungsvoll. Injektionsspritzen und -kanülen, die früher im ärztlichen Haushalt einen lächerlich geringen Posten bedeuteten, kosten heute schweres Geld; das merk jeder, der für Neuanschaffungen oder Wiederinstandsetzungen in den Beutel greifen muB.

Am besten ist die R e k ordspritze ${ }^{1}$, die heute wohl als Spritzen. modell längst die alte, oft oder meist „nicht ziehende“ Pravazspritze verdrängt hat und gegenüber Metall- und Glasspritzen vorherrscht. Sie ist am meisten zu empfehlen, da sie einfach, leicht und rasch auseinandernehmbar, aseptisch, recht widerstandsfähig und leicht zı reinigen ist; wer sparen muB, nehme sich statt $1 \mathrm{~cm}^{3}-2$ - und $5 \mathrm{~cm}^{3}$-Spritzen, die durch ihr größeres Fassung'svermögen vielseitiger benutzt werden können (Injektionen, Punktionen, Seruminjektionen) und auch nicht so leicht bei Unachtsamkeit aus der Hand fallen wie kleinere Modelle. Die sehr sauberen und gut ziehenden Glasspritzen haben den Nachteil der leichten Zerbrechlichkeit. Empfehlenswer sind auch die ,A stra"-Spritzen, deren Glaszylinder vom Arzt aus. gewechselt werden können.

An Ka nülen stehen viele Modelle zu Gebote. Die vielfach empfohlenen Goldersatznadeln finde ich nicht praktisch; sie sind nicht so scharf wie die gewöhnlichen Stahlnadeln und biegen sich sehr leicht um. Die für den Zahnarzt wohl recht zweckmäßigen Freien stein-Ka nülen, bei denen Nadel und Konus getrennt sind, eignen sich ebenfalls wenig für den praktischen Art, da ihre Zusammensetzung zu sehr aufhält. Die ideale ausglühbare Platiniridiumnadel, die nie rostet, ist leider zu teuer, wenn sie sich auch auf die Dauer, besonders für die Außenpraxis, mehr als bezahil macht; ich besitze zwei Nadeln aus schöneren und besseren Zeiten; sie haben 2 Tropenjahre und 4 Kriegsjahre überdauert und sind heute noch wie neu. Im allgemeinen reichen die üblichen vernickelten $S t a h l r e k o r d n a d e l n$ bei richtiger Behandlung völlig aus; sie haben den besonderen Vorteil, daß sie gerade die richtige Härte und die richtige Elastizität besitzen. Man nimmt am besten mittelkräftige Nadeln, die auch ölige Flüssigkeit (Kampferöl, Terpentin) gut ansaugen, und hält sich spitz-: geschliffene für Unterhaut- und Muskeleinspritzungen und kurz abgeschliffene für Blutadereinspritzungen. Letztere benutze man nie für andere Zwecke, da sie sonst stumpf werden und die intravenöse, ja nicht immer einfache Injektion außerordentlich von der Benutzung einer scharfen, glatten, kurzabgeschliffenen Nadel abhängt; langabgeschliffene Nadeln durchstoßen bekanntlich sehr leicht, ehe ihr Lumen in der Ader liegt, die gegenüberliegende Venenwand. Für intravenöse Injektionen sind die Goldersatznadeln ganz gut brauchbar ("Regold"nadeln).

Als Aufbewahrungsflüssigkeit habe ich vielerlei versucht; Alkohol zieht zu schnell Wasser an, sodaß Rosten nicht ausbleibt, auch das vielfach gerühmte Paraffinum liquidum, das außerdem unangenehm pappig ist, schützt ebenfalls nicht vor Rost Seit 2 Jahren benutze ich mit gutem Erfolg eine mir von Dr. med. Petsch, Zahnarzt in Gießen, empfohlene Desinfektionsflüssigkeit, die aus der Freiburger Universitätśfrauenklinik stammen soll : Rp. Acid. carb. liquef. 3,0, Boracis 15,0, Formol 20,0, Aqu. dest. ad 1000,0. Die Kanülen liegen in zwei gedeckelten Petrischalen - die subkutanen bzw. intramuskulären und die intravenösen getrennt - in dieser Flüssigkeit, in der sich die Kanülen sehr lange rostfrei erhalten. In einem kleinen, zur Hälfte mit der gleichen Lösung gefüllten Becherglas stehen die Spritzen, die durch. Anziehen des Kolbens ebenfalls voll Lösung gesaugt sind, zusammen mit einer Pinzette, die - das Herausnehmen der. Nadeln aus der Flüssigkeit schnell, sauber und bequem ermöglicht. Die Pinzette kann auch durch eine Klemme ersetzt werden; ich benutze letztere als sehr bequemes Fixierinstrument bei intravenöser Injektion, indem ich den Kanülen-

1) M. E. braucht der Praktiker 4 kleine Spritzen (am besten 2 g) fuir Sprechstunde, fuir Besuche, Geburtstasche und Ersatz! Nie Spritze aus Geburtstasche entleihen. da es sehr peinlich ist, wenn man ohne Spritze einer Nachgeburtsblutung gegentibersteht.
$\mathrm{Zu}$ Serum- und Salvarsaninjektionen, Lokalanäthesie sind 2 Spritzen zu $10 \mathrm{ccm}$ nötig 
konus - Lichtung des Spitzenabschliffes nach oben! - in der Klemme fest fixiere und so einen sehr handlichen, bequem und leicht $\mathrm{zu}$ lenkenden Ersatz für die Straußsche Kanüle herstelle (vğl. meine Veröffentlichung Med. Klin. 1920 H. 47). In den Kanülenschalen liegen stets einige Res e r v e ma ndrins (die man beim Kanüleneinkauf nicht vergessen darf!), damit man niemals unterläßt, die Kanïlenlichtung mit einem Drähtchen zu versehen, was für die Haltbarkeit und Benutzungsdauer der Nadeln von Bedeutung ist; das Fassen der Drähtchen beim Entfernen und Einführen ist ebenfalls durch Benutzung der bequem bereitstehenden Pinzette sehr erleichtert und aseptischer als das Anfassen mit den Fingern. Ueber das Becherglas mit Spritzen und Pinzette stülpe man als Staubschutz einen Glassturz (z. B. in Heiligenbilderhandlungen, Uhrmacherläden zu kaufen, billiger durch ein umgedrehtes Einmacheglas zu ersetzen). Zur Spritzeneinrichtung gehört ferner ein Jodtinkturfläschchen mit festem Glaspinselstopfen ${ }^{1}$ ) und ein kleines, weithalsiges Glas mit Glasstopfen von etwa 50 bis $100 \mathrm{~cm}^{3}$, gefüllt mit Alkoholäther $\bar{a} \bar{a}$ zum Durchspritzen und Reinigen der Spritze nach vollzogener Injeltion. Wichtig ist das Durchspritzell mit Alkoholäther und völliges Austrocknen durch mehrfaches Luftansaugen v or Injektionen von Organextrakten, die sehr empfindlich gegen manche Desinfektionsstoffe sind und leicht in ihrer Wirksamkeit beeinträchtigt werden. Der rasche, reibungslose Ablauf der Spritzenbenutzung fordert ferner genügenden Platz für das Beiseitestellen der abgehobenen Pétrischalendeckel und des Glassturzes.

Die kleine „Spritzeneinrichtung“ ist einfacher zu organisieren, als man sie beschreiben kann; sie lohnt sich und spart dem Arzt - man gewöhnt sich rasch an die einzelnen Handgriffe - viel Mühe, Arbeit, Aerger, Zeitverlust und Kosten. 